\title{
PERSPECTIVA DIALÓGICA DE EDUCAÇÃO E DE LEITURA: ALGUMAS REFLEXÕES ${ }^{1}$
}

\section{DIALOGICAL PERSPECTIVE OF EDUCATION AND READING: SOME REFLECTIONS}

\author{
Maria de Fátima Xavier da Anunciação de Almeida ${ }^{2}$
}

\begin{abstract}
Resumo: Neste trabalho realizamos uma reflexão teórica para pensarmos nas ressonâncias trazidas pelas teorias de educação e de leitura que fossem bases à prática educativa do/a professor/a de português. Apropriamo-nos dos referenciais de educação de Paulo Freire e do pensamento filosófico-linguístico de M. Bakhtin e de pensadores de seu Círculo linguístico, uma vez que o/a professor/a de português, no continum de sua formação, necessita se apropriar de teorias de educação, linguagem e de leitura para fundamentar a sua prática docente. Isso significa dizer que em toda prática educativa há um posicionamento político, pois não existe prática educativa neutra, apolítica. Demonstramos a nossa tese apresentando os fundamentos de educação de Paulo Freire e de leitura (linguagem) de M. Bakhtin. A dialogicidade, para Freire, é a essência da educação como prática da liberdade, da educação problematizadora. Desse modo, o diálogo é um fenômeno humano, que se configura na palavra, sendo essa um meio para que o realize. Já Bakhtin teoriza a leitura como compreensão responsiva, por isso, ativa, do tema da enunciação, ou seja, no ato de ler - compreender/construir sentidos - o leitor necessita compreender os sentidos completos, únicos da enunciação dentro do contexto de sua produção.
\end{abstract}

Palavras-chave: Leitura; educação; dialógico.

\begin{abstract}
In this paper we conduct a theoretical reflection to think of the resonances introduced by theories of education and reading that were the bases for educational practice of the Portuguese theacher. Appropriated in the references of Paulo Freire education and the philosophical-linguistic thought of M. Bakhtin and thinkers of his linguistic circle, since the Portuguese teacher in the continuum of their training, needs to appropriate theories of education and reading to support their teaching practice. This means that in every educational practice there is a political position, because there is no educational practice neutral, apolitical. We demonstrated our thesis presenting the fundamentals of Paulo Freire education and reading (language) of M. Bakhtin. The dialogical, for Freire, is the essence of education as a practice of freedom, the education that problematize. Thus, dialogue is a human phenomenon, which is configured in the word, this being a means to accomplish that. Already Bakhtin theorizes how responsive reading comprehension, so, active, the subject of enunciation, that is, the act of reading - understand/ construct meaning - the reader needs to understand the full, unique senses of enunciation within the context of their production.
\end{abstract}

Keywords: Reading; education; dialogical.

Neste artigo realizamos uma reflexão teórico-crítica para pensarmos nas ressonâncias trazidas pelas teorias de educação e de leitura ${ }^{3}$ que fossem bases para a prática educativa do/a professor/a de português. Nesse sentido, apropriamo-nos dos referenciais de educação de Paulo Freire e do pensamento filosófico-linguístico de M. Bakhtin e de pensadores de seu Círculo linguístico, uma vez que o/a professor/a de português, no continum de sua formação, necessita

\footnotetext{
${ }^{1}$ Reflexões, com algumas adaptações, as quais foram apresentadas em Comunicação no $19^{\circ}$ Congresso de Leitura do Brasil - COLE - Unicamp/SP/ julho/2014.

${ }^{2}$ FE/UNICAMP.

${ }^{3}$ Utilizamos esse enunciado como compreensão ativa, responsiva e dialógica do sujeito, diante do texto verbal e não-verbal.
} 
se apropriar de teorias de educação, de linguagem e de leitura para fundamentar a sua prática docente. Assim, saberá o que ensinar, para que e por que ensinar leitura(s) na escola.

Pensamos que o trabalho pedagógico do/a professor/a de língua materna com a leitura na escola, prescinde de teorias de leitura e de educação para fundamentar a prática docente. Isso significa dizer que em toda prática educativa há um posicionamento político, pois não existe prática educativa "neutra, descomprometida, apolítica". (FREIRE, 2001, p. 37) Demonstramos a nossa tese apresentando os fundamentos de educação de Freire e de leitura (linguagem) de Bakhtin.

\section{Educação dialógica em Paulo Freire}

Em sua principal obra: Pedagogia do Oprimido (2013[1967]), Paulo Freire aponta para o leitor os fundamentos de uma educação dialógica e libertadora. Nela o autor tece vários argumentos para demonstrar seu ponto de vista sobre o tema. A dialogicidade, segundo ele, é a essência da educação como prática da liberdade, da educação problematizadora. Isso significa que o diálogo é um fenômeno humano, que se configura na palavra, sendo essa um meio para que o realize. Há duas dimensões importantes constitutivas da palavra que medeia o diálogo:

[...] ação e reflexão, de tal forma solidárias, em uma interação tão radical que, sacrificada, ainda que em parte, uma delas, se ressente, imediatamente, a outra. Não há palavra verdadeira que não seja práxis. Daí que dizer a palavra verdadeira seja transformar o mundo. (FREIRE, 2013 [1967], p. 107)

A palavra que não serve para transformar a realidade, para Freire (2013 [1967]), é inautêntica, resulta da dicotomia que se estabelece entre ação e reflexão, "[...] esgotada a palavra de sua dimensão de ação, sacrificada, automaticamente, a reflexão também, se transforma em palavreria, verbalismo, blá-blá-blá.” (FREIRE, 2013 [1967], p. 108). Para o filósofo, a existência humana já pressupõe pronunciar o mundo, modificá-lo. O homem se faz na palavra, no trabalho e na ação-reflexão. Podemos dizer que o homem é essencialmente falante constitui-se pela linguagem (palavra).

Na sequência, adverte-nos Freire que a palavra verdadeira, que é trabalho, práxis, transformação do mundo, não é privilégio de alguns homens, mas direito de todos eles. "Precisamente por isto, que ninguém pode dizer a palavra verdadeira sozinho, ou dizê-la para os outros, num ato de prescrição, com o qual rouba a palavra aos demais." (FREIRE, 2013, p. 109).

Percebemos o ponto central da concepção de educação libertadora e problematizadora que Freire construiu: o diálogo, tendo a palavra que diz o mundo, na práxis, para que o homem consiga transformar a realidade em que vive.

Pelo diálogo (palavra), Freire (2011, p. 140) propunha uma educação que fosse capaz de contribuir para a inserção do povo, apanhando-o "[...] na emersão que fizera com a "rachadura da sociedade", fosse capaz de promovê-lo da transitividade ingênua à crítica. Somente assim evitaríamos a sua massificação."

O autor se questiona como proporcionar tal educação em que o homem não alfabetizado consiga superar as suas atitudes mágicas ou ingênuas diante de uma realidade antidemocrática, como a do Brasil dos anos de 1960. Diante dessa problemática, obtém a resposta ao criar um método de alfabetização que fosse ativo, dialogal, crítico e criticizador; que tivesse um conteúdo programático da educação modificado e que possibilitasse o uso de técnicas como a da redução e da codificação. Desse modo, poderia proporcionar a esse homem passar de uma consciência ingênua à crítica.

A base do método de alfabetização criado é o diálogo, no que defende Freire que o diálogo 
É uma relação de A com B. Nasce de uma matriz crítica e gera criticidade (Jaspers). Nutre-se do amor, da humildade, da esperança, da fé, da confiança. Por isso, só o diálogo comunica. E quando os dois polos do diálogo se ligam assim, com amor, com esperança, com fé um no outro, se fazem críticos na busca de algo. Instala-se, então, uma relação de simpatia entre ambos. Só aí há comunicação. (FREIRE, 2011, p. 141)

Constatamos que Freire relaciona diálogo à comunicação entre os homens, para que busquem, de modo crítico, por isso consciente, compreenderem a realidade histórica em que vivem e a transformarem. Ele propõe que o homem, sujeito ativo, tome a sua palavra para, também, dizer o mundo, já que a formação política do Brasil de seu tempo histórico ocorreu o que o autor denominou de "sociedade fechada", antidemocrática e no silenciamento do povo.

\section{Leitura dialógica no pensamento de M. Bakhtin}

Para entendermos o que é a leitura em Bakhtin, precisamos conhecer a natureza real do fenômeno linguístico, e ao mesmo, tempo verificar como entende a compreensão e a significação. Para Cereja (2005, p. 218), "Não se pode, dentro do pensamento bakhtiniano, trabalhar produção e construção de sentidos sem levar em conta a significação e o tema." E completo a ideia do autor: precisamos compreender, também, a natureza da linguagem e a relação dessa linguagem, que medeia a comunicação do sujeito com o outro numa dada realidade social, histórica e ideológica.

Com o objetivo de compreender a natureza da linguagem e os demais problemas relacionados a ela, Bakhtin/Volochinov (1988) apresentam de modo geral, o que entendem por compreensão, significação e tema, as quais são tratadas dentro de uma perspectiva marxista, já que anteriormente a essa iniciativa teórica, no pensamento filosófico linguístico do Século XX, haviam duas correntes, denominadas pelos autores de "objetivismo abstrato" e "subjetivismo idealista", que não deram conta de compreender o caráter vivo - por conseguinte dialógico - histórico, social e ideológico da linguagem, e, também que a compreensão é ativa, responsiva e dialógica.

Ao proporem uma teoria da compreensão ativa, Bakhtin/Volochinov (1988) vão tratar do tema e da significação para mostrarem o que é o problema da compreensão, o que entendem por compreensão. Consideram que qualquer tipo de compreensão deve ser ativa e conter o germe de uma resposta. Só a compreensão ativa nos permite apreender o tema, pois a evolução não pode ser apreendida senão com a ajuda de um outro processo evolutivo. Compreender a enunciação de outrem significa orientar-se em relação a ela, encontrar o seu lugar adequado no contexto correspondente. A cada palavra da enunciação que estamos em processo de compreender, fazemos corresponder uma série de palavras nossas, formando réplica. Quanto mais numerosas e substanciais forem, mais profunda e real é a nossa compreensão (BAKHTIN/VOLOCHINOV, 1988, p. 131-132).

Entendemos que somente a compreensão ativa permite-nos apreender o tema, que os autores consideram como a propriedade de cada enunciação em possuir um sentido definido e único, uma significação unitária, um sentido completo, construído dentro de um determinado contexto. Pelo fato do tema ser único, podemos definir a enunciação. "O tema da enunciação é na verdade, assim como a própria enunciação, individual e não reiterável. Ele se apresenta como a expressão de uma situação histórica concreta que deu origem à enunciação." (BAKHTIN/VOLOCHINOV, 1988, p. 128) Assim, a enunciação como o tema tem um sentido único, completo, individual e não reiterável, e é a expressão de uma situação histórica concreta que lhe deu origem.

É relevante também que, para os autores 
A compreensão é uma forma de diálogo; ela está para a enunciação assim como uma réplica está para a outra no diálogo. Compreender é opor à palavra do locutor uma contrapalavra. Só na compreensão de uma língua estrangeira é que se procura para cada palavra uma palavra equivalente na própria língua. (BAKHTIN/VOLOCHINOV, 1988, p. 132).

Desse modo, por meio dessas ideias, percebemos que a leitura num viés bakhtiniano é a compreensão em forma de diálogo, uma vez que é um ato de um sujeito que lê um texto dentro de um contexto concreto, histórico, social e ideológico que atribui respostas ao lido, dá a sua contrapalavra ao que leu e compreendeu. Por conseguinte, constrói sentidos ao compreender um texto. Construir sentidos é uma atividade de compreensão responsiva, ativa e dialógica.

Diante da tese de Bakhtin/Volochinov (1988) de que a compreensão é uma forma de diálogo, pensamos que a leitura, como compreensão, e a construção de sentidos são dialógicas, porque pressupõem repostas e contrapalavras do leitor. $\mathrm{O}$ ato de ler implica a compreensão e a construção de sentidos do lido como forma de diálogo, por isso ao responder ativamente, dar a sua contrapalavra ao lido, o leitor, que é um sujeito sempre situado socialmente, constrói sentidos, atribui um índice de valor, aprecia, concorda, discorda do que leu no discurso do outro.

Nesse sentido, a palavra diálogo não pode ter apenas uma significação positiva que remete a "solução de conflitos", a "entendimento" e a "geração de consenso", por isso, os membros do Círculo de Bakhtin

[...] tentam dar conta da dinâmica das relações dialógicas num contexto social dado e observam que essas relações não apontam apenas na direção das consonâncias, mas também das multissonâncias e dissonâncias. Delas pode resultar também a convergência, o acordo, a adesão, o mútuo complemento, a fusão, quanto a divergência, o desacordo, o embate, o questionamento, a recusa. (FARACO, 2006, p. 66)

Ao ler, compreender e ao construir sentidos com e de um texto, o sujeito leitor estabelece um diálogo com o texto lido e o com o outro, o autor do texto, dá uma resposta ativa, posicionase de modo que aceita ou rejeita as ideias do outro no texto. Por isso, lembremos que para Bakhtin, segundo Fiorin (2006), a propriedade da língua em seu caráter vivo, concreto, em seu uso real, é ser dialógica. Não se trata, apenas, das relações dialógicas face a face, mas

Ao contrário, todos os enunciados no processo de comunicação, independente de sua dimensão, são dialógicas. Neles, existe uma dialogização interna da palavra, que é perpassada sempre pela palavra do outro. Isso quer dizer que os enunciados, para constituir um discurso, leva em conta o discurso de outrem, que está presente no seu. Por isso, todo discurso é inevitavelmente ocupado, atravessado, pelo discurso alheio. O dialogismo são as relações de sentido que se estabelecem entre dois enunciados. (FIORIN, 2006, p. 19)

Com a citação acima, pensamos que o sujeito acessa a realidade pela mediação da linguagem, por meio do discurso do outro, da palavra do outro, logo, no ato de ler textos (verbais ou não), por meio da construção de sentidos que produz ao lê-los, dentro de relações dialógicas produzidas nesse ato. Esse ato não é solitário, no sentido de que o sujeito leitor sempre lê o texto do outro, compreende-o com o seu mundo vivido para dar uma resposta ao lido, dentro de um contexto social, histórico e ideológico. Trata-se de uma compreensão ativa, responsiva, portanto dialógica do texto, por isso a leitura passa pela compreensão responsiva, dialógica da enunciação do outro. 
Outro ponto a destacar é a dinâmica da criação ideológica que acontece na dialogicidade de todo dizer, que é apresentada por Bakhtin, conforme Faraco (2006) em três dimensões:

a) todo dizer não pode deixar de se orientar para o "já dito". Nesse sentido, todo enunciado é uma réplica, ou seja, não se constitui fora daquilo que chamados hoje de memória discursiva;

b) todo dizer é orientado para a resposta. Nesse sentido, todo enunciado espera uma réplica e - mais - não pode esquivar-se à influência profunda da resposta antecipada. Neste sentido, possíveis réplicas de outrem, no contexto da consciência socioaxilógica, têm papel constitutivo, condicionante, do dizer, do enunciado. Assim, é intrínseco ao enunciado o receptor presumido, qualquer que ele seja: o receptor empírico entendido em sua heterogeneidade verboaxilógica, o "auditório social" [...] ou A construção do enunciado, [...] o "superdestinatário", [...] o "terceiro" nos termos discutido por Bakhtin em $\mathrm{O}$ problema do texto [...].

c) todo dizer é internamente dialogizado: é heterogêneo, é uma articulação de múltiplas vozes sociais (no sentido em que hoje dizemos ser todo discurso heterogeneamente constituído), é o ponto de encontro e confronto dessas múltiplas vozes. Essa dialogização interna será ou não claramente mostrada; o dizer alheio será ou não destacado como tal no enunciado ou, para usar uma figura recorrente em Bakhtin, será aspeado ou não, em escalas infinitas de graus de alteridade ou assimilação da palavra alheia [...]. (FARACO, 2006, p. 58 - grifos do autor.)

No ato de ler, de compreender e de construir sentidos o leitor diz algo ao já dito, ele responde ao já dito, encontra-se e se confronta com as múltiplas vozes apresentadas nos sentidos produzidos pelo outro no texto.

\section{Algumas considerações}

As ressonâncias das teorias de educação em Paulo Freire e de leitura (linguagem) em Bakhtin, que podem fundamentar a prática educativa do/a professor/a de português, ao trabalhar a leitura na escola, mostram-nos concepção de diálogos distintos, entretanto, são fundamentos teóricos que tratam o homem como sujeito ativo e crítico diante do conhecimento e da produção de sentidos. Trata-se de um sujeito que interfere na realidade, posiciona-se ao mundo quando o lê.

Desse modo, a teoria de educação dialógica proposta por Freire, inicialmente voltada à alfabetização de adultos, transpõe essa área, e pode se tornar referência à prática educativa do professor/a, que ministra aula de língua portuguesa na escola.

Podemos dizer que Freire inaugura um novo paradigma de educação no Brasil, especificamente da educação popular, tendo como foco a alfabetização voltada a jovens e adultos, no país e em âmbito mundial. Isso não significa que deixamos de lado a dialética, as contradições entre antigos e novos modelos de pensar a realidade, na construção de novos paradigmas voltados à educação e ao ensino escolarizado nesse país.

Já M. Bakhtin teoriza a leitura como compreensão responsiva, por isso, ativa, do tema da enunciação, ou seja, no ato de ler - compreender/construir sentidos - o leitor necessita compreender os sentidos completos, únicos da enunciação dentro do contexto de sua produção. Ler pressupõe um sujeito leitor e um texto a ser lido, que é produzido por outro sujeito - o autor. Trata-se de pensar num leitor ativo, porque constrói sentidos ao compreender o tema do que leu por meio do texto do outro. Constatamos uma relação dialógica no ato da leitura, pois tanto leitor como o texto do outro está no foco desse ato, que possibilita a construção das relações de sentidos. 
O pensamento do filósofo da linguagem também é referência na área dos estudos da linguagem, ao propor uma teoria da leitura dialógica dentro de uma perspectiva sócio-históricoideológica, que pode ser referência no trabalho educativo do/a professor/a de português com o ensino da leitura na escola.

\section{Referências}

BAKHTIN, Mikhail; VOLOCHÍNOV. V. N. Marxismo e filosofia da linguagem. Problemas Fundamentais do Método Sociológico na Ciência da Linguagem. Trad. Michel Lahud e Yara Frateschi Vieira com colaboração de Lúcia Teixeira Wisnik e Carlos Henrique D. Chagas Cruz. 4. ed. São Paulo: Hucitec, 1988 [1977].

BAKHTIN, Mikhail. Estética da Criação Verbal. Trad. Paulo Bezerra. 4. ed. São Paulo: Martins Fontes, 2003 [1992].

CEREJA, Magalhães. Significação e tema. In: BRAIT, Beth (Org.). Bakhtin: Conceitos-chave. São Paulo: Contexto, 2005.

FARACO, Carlos Alberto. Linguagem e diálogo: as ideias linguísticas do círculo de Bakhtin. 2. ed. São Paulo: Criar Edições, 2006.

FIORIN, José Luiz. Introdução ao pensamento de Bakhtin. 1. reimp. São Paulo: Ática, 2006.

FREIRE, Paulo. Política e educação. 5. ed. São Paulo: Cortez, 2001.

FREIRE, Paulo; SHOR, Ira. Medo e ousadia: o cotidiano do professor. 10 ed. Trad. Adriana Lopez. São Paulo: Paz e Terra, 2003.

FREIRE, Paulo. Educação e mudança. 32. reimp. São Paulo: Paz e Terra, 2010.

FREIRE, Paulo. Educação como prática da liberdade. 14. ed. rev., atual. Rio de Janeiro: Paz e Terra, 2011.

FREIRE, Paulo. Pedagogia do oprimido. 54. ed. rev., atual. Rio de Janeiro: Paz e Terra, 2013.

ZITKOSKI, Jaime José. Paulo Freire \& a Educação. 2. ed. Belo Horizonte: Autêntica Editora, 2010.

\section{Sobre a autora}

Maria de Fátima Xavier da Anunciação de Almeida. Pós-doutoranda em Educação/ Depto DELART - FE/UNICAMP. Doutora em Letras/ Universidade Presbiteriana Mackenzie; Mestre em Educação/UFMS. Professora Adjunta do Curso de Pedagogia da Faculdade de Educação/Universidade Federal de Mato Grosso do Sul. Participa dos Grupos de Estudos e Pesquisas ALLEAULA/UNICAMP; GEFORPED/UFMS e GEPEH/UFMS.

E-mail: mfatima.ead.ufms@gmail.com.

Cel.: (67) 98407-9207. 